\title{
2016 Annual Statistical Analysis Report of Research Paper of Sichuan Technology and Business University
}

\author{
Zongshan Pu${ }^{1, a}$, Liqun Xiao ${ }^{1, b}$, Yiran Huang ${ }^{1, c}$, Hongping Bai, ${ }^{1, d}$ \\ ${ }^{1}$ Sichuan Technology and Business University, Sichuan, Chengdu, 611745
}

Keywords: Academic Paper, Statistical Analysis, Periodicals

\begin{abstract}
The analysis statistic of CNKI Periodicals and papers is a valuable reference to assess the science research .Statistics after 2016 shows that the amount of papers delivered by Sichuan Technology and Business University tends to increase and Sichuan Technology and Business University ranks in the forefront compared with the similar institutions. Research hotspots mainly focus on areas like non-government funded education, teaching, education reform and social sciences account for a large part of the hotpots. However, the quality of the periodicals is not very good on the whole. On one hand, the number of core thesis and core authors is not considerable. On the other hand, there are a few people who cite these of Sichuan Technology and Business University. In a word, all that I have mentioned shows that the science research papers are still in a stage that only care about the amount of papers.
\end{abstract}

\section{Research Contents and Methods}

We did a search by the full-text data base of the CNKI Periodicals. The condition for search is what will mention next. The channel and time, should be restricted to " literature" and January, 1st, 2016- December. The institution option should be put in "Sichuan Technology and Business University" or "Chengdu College of Sichuan Normal University", The search result is 339pieces of papers. When we get the result, we do duplicate removal according to the output, get rid of the writer's announcement, important enlightenment, wrong data , pre-published repeated data and so on. After all these steps, we selected periodicals and papers whose first author belongs to Sichuan Technology and Business University. And we get to know that the number of periodicals of our school is 324. Taking advantage of the bibliometric, we did a quantitative analysis about the department distribution, the papers author, thesis and periodicals delivery and so on. The report is as follows.

\section{The Analysis about the Delivery Tendency of the Periodicals}

According to the recent analysis about our school's papers during the past decade by the CNKI, the total volume of academic papers is 1210 . At corn goes current growth rates, the number of recruited papers by CNKI will be 400 in 2017. Details see the trend of periodical document delivery between 2007-2017. (Fig. 1). 


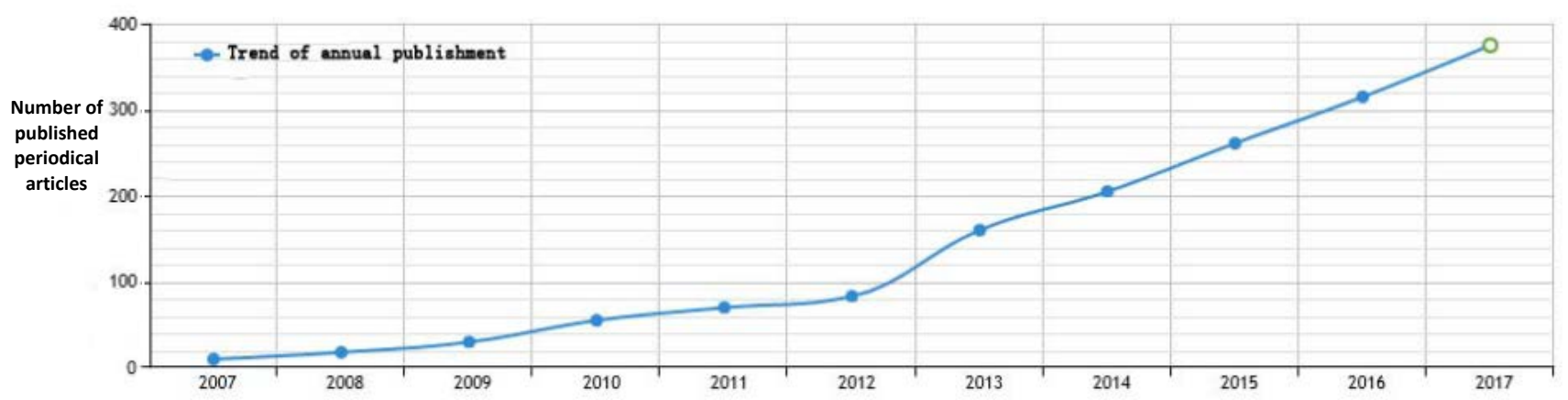

Fig. 1 Frend of periodical document delivery

\section{A Comparative the Analysis of the Collected Documents by the CNKI in the Same Area and Same Institutions in 2016}

Taking advantage of the CNKI whole text data base and search 10 colleges in 2016 like Jincheng college of Sichuan University 410, Jinjiang college of Sichuan University 90, Sichaun University of Media and Communication 197, Chengdu College of Arts and Sciences 142, Tianfu College of Southwestern University of Finance and Economics 134, Chengdu College of University Electronic Science and FeChnology 140, the Engineering \& Technical College of Cheng du University of Technology 157, YinXing Hospitality Management College of Chengdu Information Engineering University 99, Hope College of the Southwest Jiao Tong University 77 respectively for the literature collection. You can see the details in the CNKI Literature Collection for the Private and Independent Colleges in Sichuan Province in 2016 (Fig.2). According to the chart, we can see that our school ranks forefront in the number of paper delivery compared with the similar institutions. However, the quality of the text is expected to improve as the paper delivery has indicated.

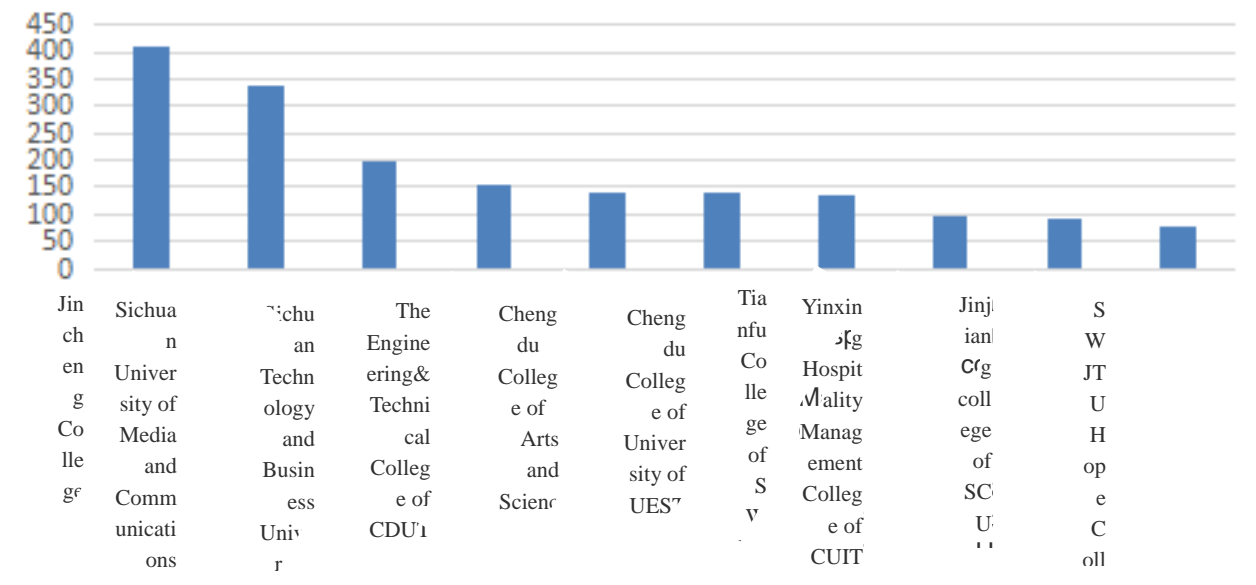

Fig. 2 CNKI Literature Collection for the private a. d Independent Colleges in Sichuan Province.

\section{Analysis of Keywords Hot Spots of Journal Papers}

According to the analysis of keywords of published papers in our college in 2016 year, the ranking top ten list of hot keywords is that: library, private colleges, colleges and universities, ideological and political education, development, reform in education, service, in dependent colleges, countermeasure. The main research field and direction of our college teachers approach to fact of private colleges, reform in education of universities and colleges, and innovation. Meanwhile, library is also becoming the crucial basement of scientific research in our college and the main driving force of reform of college. 


\section{Analysis of Research Level}

According to the analysis of research level of published papers in our college in 2016 year. $42.75 \%$ papers are the research of the research on social service field, and $12.68 \%$ of them are research on natural service field, which illustrates the emphasis of social field. Specific details see hierarchical analysis diagram of academic paper. (Fig. 3)

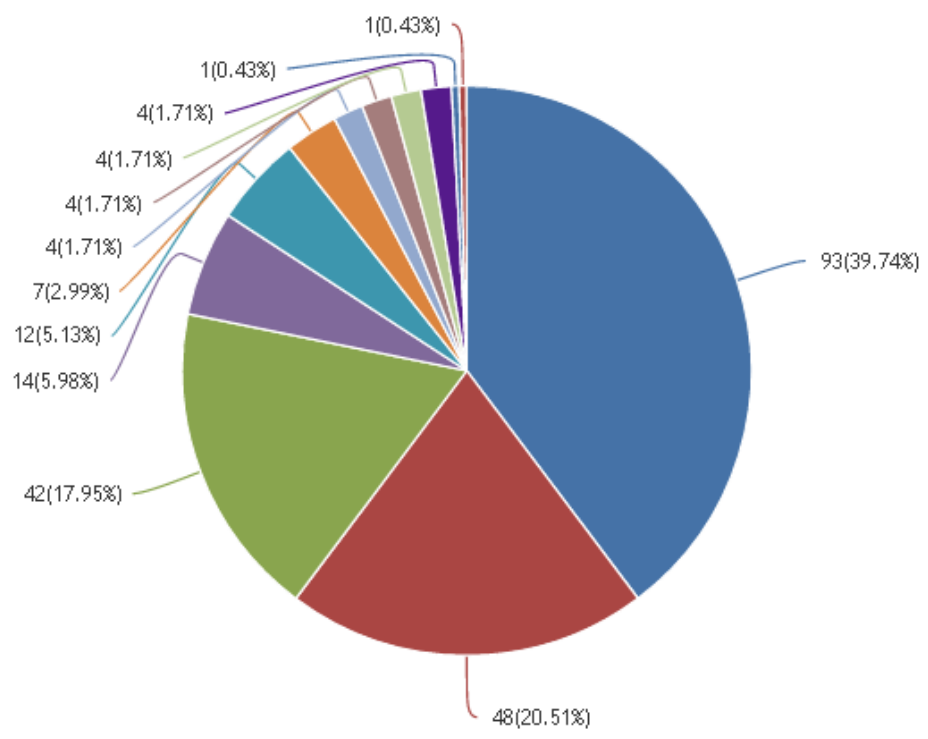

Fundamental research (social science)

Industry guidance(socail science)

Engineering

Technology(natural science)

Mass

Culture

Basic education and secondary vocational education Literary

Works

Basic and applied basic research(natural science)

Higher education

Vocational

Fig. 3 hierarchical analysis diagram of research paper

\section{The Source of Received Periodicals}

The Distribution of Documents. According to the data of CNKI, in the recent one year, the first ten documents that have been published are including Intelligence, Manager and Administrator, The Fashion of Tomorrow, Time of Education, Great Parents, Tea of Fu Jian, The Trend of Technology, The World of Telecommunication, Sino-foreign Enterprisers, and the specific number they have recorded is respectively $16,13,7,6,6,5,5,4,4$. Besides, what has recorded most in the national Chinese core periodicals is Tea of Fu Jian, which includes 5 parts that are relative to English of art major. There are main two sources: $33 \%$ is from common documents while $67 \%$ is from core documents. As time goes by, the number of core documents is increasing year by year. We also make great progress in publishing articles by both common and core documents. The details are noted in the Figure 4. 

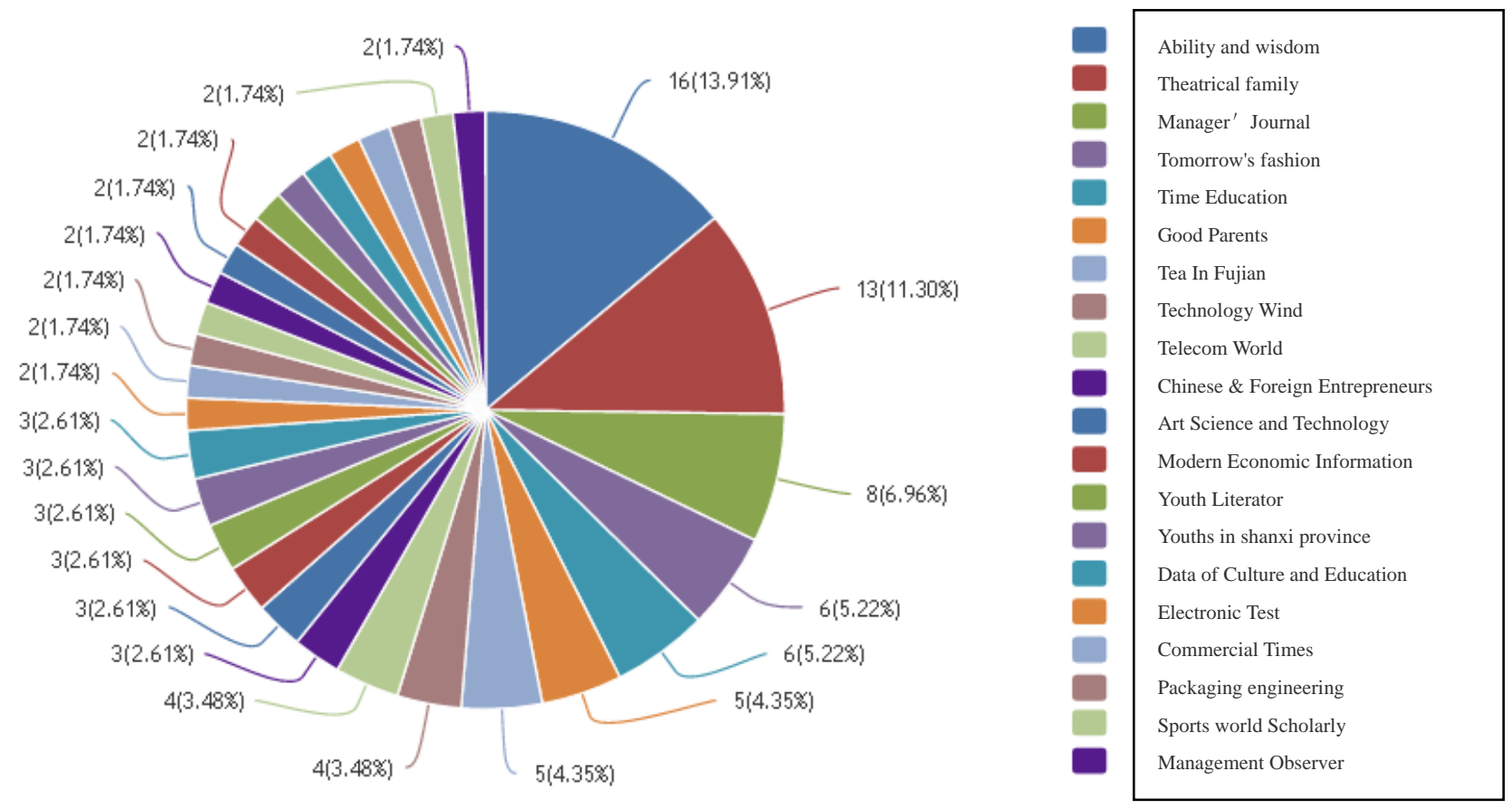

Fig.4 the journal source

The Distribution of Core and Higher-Level Documents. In the recent one year, 36 articles are recorded in core and higher-level documents, two of which are even recorded in double core documents (The core of Peking University and CSSCI). They are Management and Science of China and He Bei economy and trade University magazine. 24 core documents have published these 36 articles, 13 of which are recorded by 9 science and engineering, and 23 of which are recorded by 15 society and science documents. The specific details are noted in core and higher-level documents (Fig. 5).
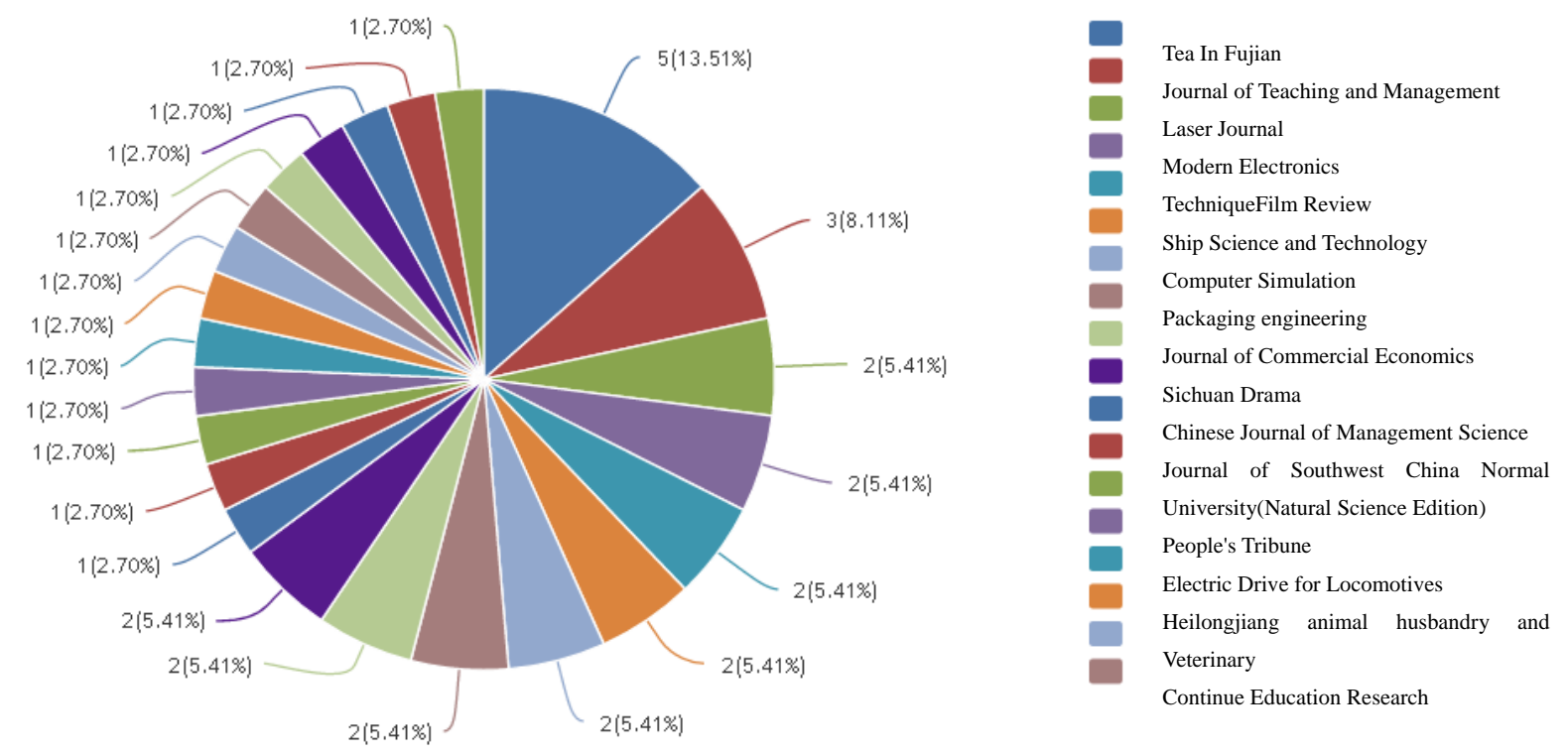

Fig.5 core higher-level documents

\section{Quantitive Analysis of Published Authors and Papers}

The Distribution of Prolific Authors. According to the analysis of research papers collected by CNKI in 2016, a lot of talented people in Sichuan Technology and Business University has published their papers. The top six prolific authors are Na Tang, Aihua Chen, Peng Zhao, Bo liu, Qiang Liu, Liqun Xiao. The following figure is above the distribution of prolific authors. 


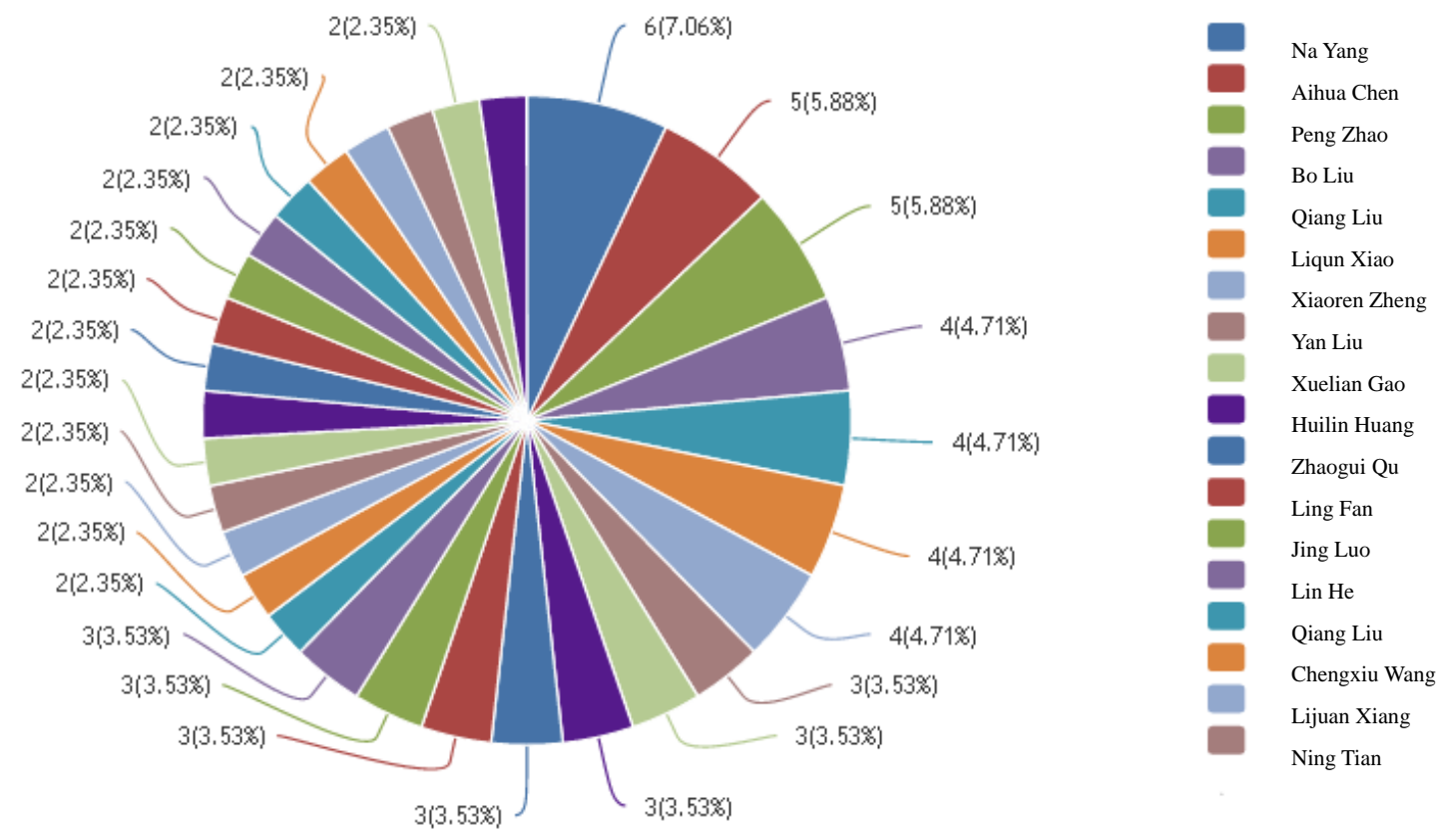

Fig. 6 the distribution of prolific authors

The Distribution of Academic Paper Fund in 2012. Among those published paper, two of them are supported by National Natural Science Fund. Thirteen of them got provincial Fund.

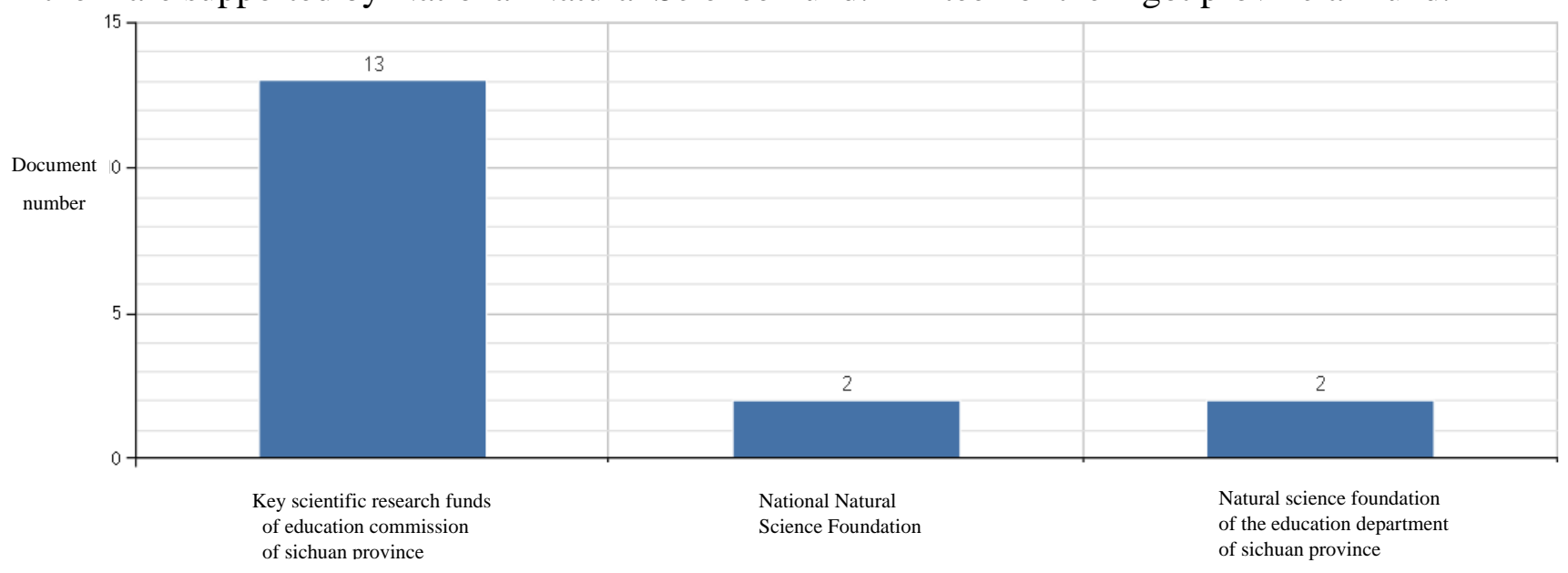

Fig. 7 The distribution of academic paper fund

\section{Conclusion}

The analysis of published papers collected by CNKI shows that there is a great improvement in academic research of Sichuan Technology and Business University. Which ranks high in the similar universities, the same region. However, compared with the key universities, there is still a long way to go. This report analyze our school's academic research ability and shows that our research has combined with the transformation of our school. Supported by our leaderships and with the effort of all teachers, academic research of our school will play an important role in our transformation and become an indispensable intellectual support of local economic. I wish the scientific research of level of Sichuan Technology and Business school to a new height 


\section{References}

[1] T.Zeng and Y.Y.Zhang. Statistical analysis of research papers of Health Qigong in Chinese sports core periodicals from 2004 to 2015 years[J]. Journal of qufu normal university (natural science edition), 2016,(04):99-103.

[2] L.J.Dong. Research on nursing management fund papers in the sight of Literature measurement analysis[D].Shanxi medical university, 2016.

[3] S.J.He. Analysis of research papers of aerobics in Chinese sports core periodicals[D]. Hebei normal university, 2016

[4] X.M.Wang, X.X.Fan, G.L.Zhou, K.F.Pan, X.Zhou, X.Qu, L.Huang, J.R.Liu, J.X.Wu, X.Z,Song, H.Cui, C.liu, L.X.Shao, Y.J.Liu and Z.L.He. Statistical analysis of research papers of The national higher education colleges and universities in 2015_-based on post count of 18 education class Chinese core journals[J]. China's higher education research,2016,(04):23-29. 